\title{
How do we improve quality in primary dental care?
}

IN BRIEF
Quality improvement is a prospective
activity in which we seek to improve care
on a continuous basis as part of everyday
routine.
- When trying to improve quality the
process of how an intervention is
implemented is at least as important as
the efficacy of the intervention itself.
Quality improvement is difficult; it
requires alignment of purpose and
activities at different levels.

\author{
S. Campbell ${ }^{1}$ and M. Tickle ${ }^{* 2}$
}

Quality improvement differs from quality assurance (which is retrospective in nature) in that it attempts to use a quality assessment cycle and focuses on the organisation or system of production as a whole. In this paper, the third in a series of three published in this Journal, we discuss the concept and evidence base of quality improvement, the main approaches that have been used in other healthcare settings and the importance of a multi-faceted strategy to address this issue. These topics are then related to the context of primary dental care and the way dentistry currently addresses quality improvement. Finally, we set out an agenda and provide recommendations for a system-based quality improvement strategy for primary dental care and identify the likely barriers and facilitators for this approach.

In the first paper $^{1}$ of this series of three, we discussed the notion of quality of care in dentistry, set against the context of some existing definitions of quality in healthcare services and settings other than dentistry. The second paper ${ }^{2}$ explored the challenges of measuring quality in primary dental care, while accepting the fact that at the moment we have no agreed definition or conceptual framework for quality in dentistry.

In this paper, we define and discuss the concept and evidence base of quality improvement, the main approaches that have been used in other healthcare settings ${ }^{3}$ and the importance of a multifaceted strategy to address this issue. We then relate these topics to the context of primary dental care and the way dentistry currently addresses quality improvement. Finally, we set out an agenda and provide recommendations for a system-based

\footnotetext{
Professor of Primary Care Research, Population Health Research Institute, affiliated to the School of Dentistry, The University of Manchester, Higher Cambridge Street, Manchester, M15 6FH; ${ }^{2}$ Professor of Dental Public Health and Primary Care, School of Dentistry, affiliated to Population Health Research Institute, The University of Manchester, Higher Cambridge Street, Manchester, M15 6FH

${ }^{*}$ Correspondence to: Professor Martin Tickle Email: martin.tickle@manchester.ac.uk; Tel: 01612756610
}

\section{Refereed Paper}

Accepted 10 May 2013

DOI: 10.1038/sj.bdj.2013.831

${ }^{\circledR}$ British Dental Journal 2013; 215: 239-243 quality improvement strategy for primary dental care and identify the likely barriers and facilitators for this approach.

\section{WHAT IS QUALITY IMPROVEMENT?}

At its simplest improvement is about shifting performance or quality or safety from a measured position to a higher or enhanced level than the starting position. It refers to activities that seek to improve care, and prevent poor care, most commonly on a continuous basis as part of everyday routine. Quality improvement differs from quality assurance (which is retrospective in nature) in that it attempts to use a quality assessment cycle and focuses on the organisation or system of production as a whole.

When considering assessment of a change in quality two fundamental distinctions must be made. The first is between internal and external assessment. ${ }^{4}$ External assessments focus on quality assurance systems to formally accredit or certify primary care organisations as meeting minimum or set standards. Internal assessments are organisation-driven exercises in quality improvement. The second distinction is between quality assuring or assessing a service against a defined acceptable (minimum) level of service using summative criteria, and educational approaches using formative criteria that show that a service is improving continuously at a standard higher than the minimum. In all cases, assessment is not a neutral activity; it requires a judgement of performance. ${ }^{4}$ Summative assessment can be seen as assessment of learning whereas formative assessment can be viewed as assessment for learning. ${ }^{5}$ The crucial distinction is between (summative) assessment to judge for example, for validation or accreditation and (formative) assessment to improve (through appropriate and effective learning). Moreover, simply measuring quality or collecting data will not guarantee improvements in quality; assessment is a snap-shot of quality and offers only a retrospective assessment, rather than attempting to improve care prospectively.

Quality improvement strategies therefore seek to engage in forward-looking 'no blame' initiatives, attempting to improve all services on a practice-bypractice basis. This approach seeks to demonstrate performance changes as the initiative progresses and sets targets for improvement that are contextually relevant. ${ }^{6}$ While most health professionals tend to overestimate their performance, ${ }^{7}$ seeing the gap between the ideal or perceived and the actual performance can help motivate people to change. ${ }^{8}$ However, educational schemes that aim to promote continuous improvement without stipulating a minimum standard may enable 
people to practice without ever achieving a minimum standard. ${ }^{9}$ As such, the balance between external/quality assurance (summative) and internal/quality improvement or educational (formative) approaches is crucial. Or to put it another way, a balance between trust and accountability is required. ${ }^{10}$ 'With support, all practices should be required to demonstrate their ability or capability to meet at least minimum standards, while aiming for excellence. ${ }^{11}$

To provide the right environment for quality improvement a focus on quality across the total healthcare system is required. This is because primary care operates within a healthcare system provided by teams within practices and organisations, even though it is delivered by and to individuals. ${ }^{3}$ Achieving quality improvement therefore requires an understanding of the need for multilevel approaches to change. These levels are:

- The individual (for example, general dental practitioner)

- The group or team (eg primary dental team in a practice)

- The overall organisation (for example, Local Professional Network within NHS England)

- The larger system (for example, National Health Service) in which individuals and organisations are embedded. ${ }^{12}$

While recognising the independence of each level, quality improvement strategies need also to consider the inter-dependence of various levels. This is because real improvement comes from changing systems ${ }^{13,14}$ and to change systems it is crucial to "take into account the context for implementation; what is important is not what works, but where and why it works" ${ }^{14}$ and 'to unpick the complex relationship between context, content, application and outcomes. ${ }^{15}$ Systems thinking ${ }^{16}$ can be used to consider quality improvement in healthcare systems, based on some underlying principles (Table 1).

As has been found in dental care settings, groups of practitioners often encounter difficulties when trying to bring about change, but it is seen as essential that they and their teams lead the process. ${ }^{17}$ Supportive and learning environments are therefore crucial, which emphasise and

\section{Table 1 Systems thinking ${ }^{16}$}

A system needs a purpose to aid people in managing interdependencies

The structure of a system significantly determines the performance of the system

Changes in the structure of a system have the potential for generating unintended consequences

The structure of a system dictates the benefits that accrue to various people working in the system

The size and scope of a system influence the potential for improvement

The need for cooperation is a logical extension of interdependencies within systems

Systems must be managed

Improvements in systems must be led

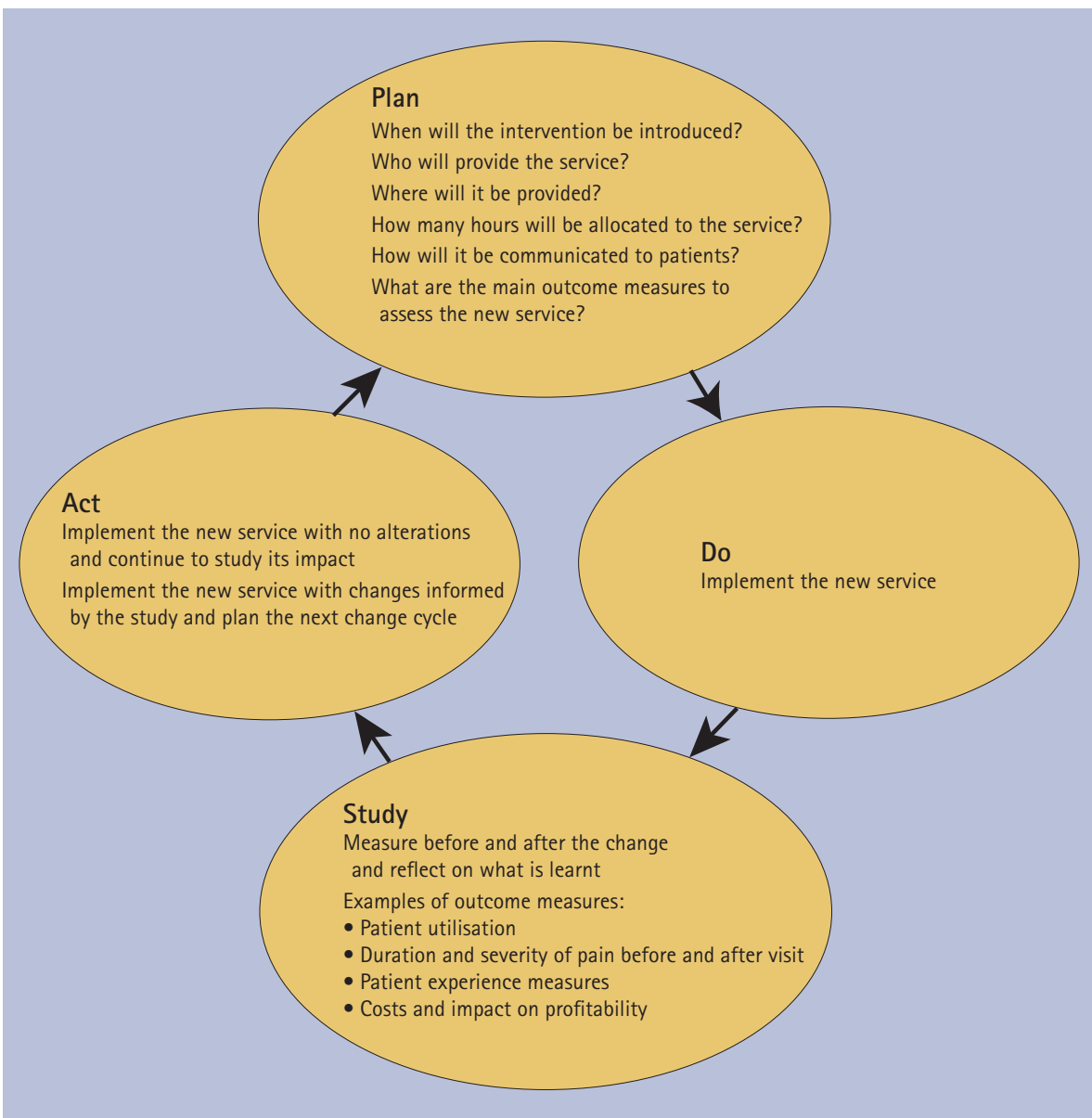

Fig. 1 Plan-Do-Study-Act cycle with a worked example of introducing a new dedicated service for patients in need of urgent care

encourage learning..$^{14}$ It is necessary, however, to distinguish between methods for implementing quality improvement strategies and examples of approaches used in healthcare to improve quality.

\section{METHODS OF IMPLEMENTING QUALITY IMPROVEMENT}

Improvement science (research focused on healthcare improvement) is now a central component of healthcare. ${ }^{18}$ Quality improvement requires a quality improvement strategy, which involves ongoing evaluation of interventions or changes made to the system. This process is often referred to as a quality cycle. Fundamentally, 'a number of methods are needed and that no single one will be sufficient to assess the full impact of quality improvement'. ${ }^{14}$ While various approaches to implement continuous quality improvement exist, "the process of improvement is more important than the specific approach or method. ${ }^{14}$ For simplicity, we focus here on two approaches to quality improvement: 


\section{Table 2 SMART-goals for change}

Specific: Clear and unambiguous plan making clear who is involved, the aim of changes, the location of change, the conditions that need to be in place, the barriers that may have to be overcome and the expected added value of the change

Measurable: The timings and frequency of measuring activities must be clear and feasible

Acceptable: There is support and buy-in for the proposed change or activity being assessed, which is crucial for the consolidation of any improvement. Attitudes, capacities, skills and resources don't impede the execution of the plans

Realistic: The planned activities have to be feasible, with realistic goals and timelines and resources to implement the change and deliver the goals

Time restricted: The improvement plan specifies the roles and responsibilities of all involved at any given stage of the plan

Table 3 Key implementation factors for quality improvement in primary dental care (based on Campbell et al. 20105; Boaden et al. 200814; Grol et al. 2005 ${ }^{30}$ )

Define quality

Address how to measure each aspect of defined quality

Decide who the customer is

Multiple approaches targeting quality and safety within a systems based strategy

Clinically led improvement (audit, clinical governance, etc) must go hand-in-hand with managerially-led performance improvement

Prioritisation of formative assessment to drive continuous quality improvement but also summative assessment to ensure minimum standards

A mix of integrated managerial/organisational, clinical and patient experience/outcome approaches

A mix of professional, financial and reputational indicators

A mix of structure, process and outcomes measures

A mix of top-down and bottom-up approaches

Validated, field-tested instruments and indicators

Data collection systems that underpin measurement before quality improvement begins ('know your baselines')

Any pay-for-performance should reward quality improvement only with quality maintenance rewarded using existing payment systems

Any pay-for-performance scheme should equal $<10 \%$ of income

Quality improvement approaches should target teams/practices and individuals

Unintended consequences should be carefully considered as well as the potential impact on different patient/population groups

Recognise the importance of whole system leadership and support for professionals and team

- Plan-Do-Study-Act [PDSA] ${ }^{14,19}$

- Specific-Measureable-AcceptableRealistic-Time restricted [SMART] ${ }^{8}$

The PDSA cycles ${ }^{19}$ are small tests of change, used as part of a continuous improvement approach. ${ }^{14}$ The idea is that a focus for improvement is identified and prioritised and a plan of action implemented that incorporates reflection as an integral component (Fig. 1). It is based around three key questions: "what are we trying to accomplish?', 'how will we know if a change is an improvement?' and 'what changes can we make that will result in an improvement?' The four stages of the PDSA cycle $^{20}$ are shown in Figure 1 with a worked example of implementing a new service in the practice that provides dedicated time for the management of patients in need of urgent care. An alternative but overlapping approach is to formulate concrete goals for change using the SMART-methodology outlined in Table 2. The SMART approach is underpinned by an improvement plan with concrete aims, targets and timelines.
To evaluate quality of care, we need: ${ }^{8}$

- Indicators that measure performance; the development and selection of valid and reliable indicators is preferred in a systematic procedure, which includes empirical testing

- Transparent and acceptable methods to calculate and feedback - indicator scores and benchmarks

- Formulation and prioritisation of concrete aims for improvement based on the measurements.

Measurement is important to gauge improvement with ongoing evaluation of the progress made during, or as a consequence of the implementation of, a new activity. ${ }^{8}$ This is in order:

- To improve the proposal for change: when targets are not easily achieved (unrealistically high) or too easily achieved (unrealistically low) they can be adapted

- To further analyse problems in changing care: when targets are not met a further analysis of the barriers and facilitating factors may be needed to better focus the implementation strategies

- To alter strategies and measures for change: when targets are not achieved other, potentially more effective, strategies may be selected

- To alter the implementation plan: not achieving the aims of a strategy may be caused by failures in the implementation process.

Any chosen intervention will be expected to produce an improvement but fundamentally, "the main issue is the way in which the improvement is implemented, rather than the nature of the improvement itself.' ${ }^{\prime 4}$ A good analogy is a clinical treatment which has been shown by randomised controlled trials to be effective if used optimally (for example, fluoride toothpaste) but if the real life processes used to implement the intervention are poorly applied (for example, the patient doesn't use the toothpaste) the anticipated benefits will not be realised.

\section{EXAMPLES OF APPROACHES TO QUALITY IMPROVEMENT IN HEALTHCARE}

A variety of different approaches have been used to drive quality improvement 
in healthcare. ${ }^{21,22}$ 'These include medical audit, evidence based guidelines, accreditation, disease management, public reporting of performance indicators, financial incentives, revalidation of professionals, and breakthrough collaboratives. Research on the effect of these approaches is scarce, but the evidence shows that even well developed improvement programmes are often only partially effective. ${ }^{21}$ Evidence from primary medical care settings suggests that most quality improvement methods have short-term effects. For example, the effects of financial incentivisation are often short-term and worldwide, the evidence base for provider pay-for-performance is not compelling and can be summarised as 'small gains at large cost' with most incentives attached to meeting a set target rather than continuous quality improvement. ${ }^{23-25} \mathrm{~A}$ recent review of the impact of the GPQOF concluded that 'observed improvements in quality of care for chronic diseases in the framework were modest, and the impact on costs, professional behaviour, and patient experience remains uncertain'. ${ }^{26}$ Other methods have also shown the same short term effects, for example audit and feedback, ${ }^{27}$ accreditation, ${ }^{28}$ or feedback to primary care providers on patient evaluations of care. ${ }^{29}$ The literature therefore reinforces the importance of implementing a range of coherent, multi-level interventions across a system within a quality improvement strategy, rather than individual interventions used in isolation. ${ }^{12,21}$ Combinations of interventions are also more likely to change professional behaviour rather than isolated initiatives. ${ }^{30}$

A multifaceted approach is therefore required with a focus on quality improvement at the macro-meso-and micro levels of service delivery. Any single approach, for example the use of indicators or educational interventions, should be integrated within broader quality improvement programmes. Just as defining ${ }^{1}$ and measuring ${ }^{2}$ quality have been seen as complex issues, improving quality is also complex and requires a mix of approaches. These will combine formative and summative, internal and external, subjective and objective approaches ${ }^{3,30-32}$ with a combination of objective metrics and reflective practice having considerable quality improvement potential. $^{32}$

\section{WHAT ARE THE LESSONS FOR DENTISTRY?}

The research evidence base for quality improvement in primary dental care settings is sparse. However, the limited literature shows that similar approaches have been used to other primary care settings such as clinical audit, ${ }^{33}$ patient evaluation, ${ }^{34}$ indicators ${ }^{35}$ and collaboratives. ${ }^{36}$ Sbaraini $^{34}$ and colleagues show how, in Australian primary dental care settings, patients value having a supportive and caring dentist and a dedicated dental team, which has obvious resonance with primary medical care. ${ }^{37}$ Quality improvement collaboratives provide enhanced strategies for learning and change for disseminating healthcare innovations in environments where 'diverse participants learn, listen, reflect, and share together can enable them to take back to their own organisations key messages and change strategies that benefit them the most. ${ }^{36}$ The Department of Health is currently undertaking pilots to inform a new dental contract using different models of remuneration; piloting includes a preliminary Dental Quality Outcomes Framework (DQOF). ${ }^{35}$ The initial experience of quality indicators within NHS dentistry has not been a good one ${ }^{38}$ but evaluations are ongoing and the application of these methods and processes are in their infancy in dentistry. These initial attempts at quality improvement have focused on individual interventions at specific levels and there has been little recognition from the literature that a whole systems approach is needed for continuous quality improvement. The recent policy changes in the NHS in England that aim to work towards a clinically led, patientfocused, outcome driven system, ${ }^{39}$ the NHS structural changes with dentistry being centrally commissioned by NHS England and local clinical leadership of the system through Local Professional Networks, the move to a system of remuneration which seeks to reward quality ${ }^{35}$ plus regulatory changes including the introduction of revalidation, ${ }^{40}$ all seem to be pushing in the same direction: to facilitate the required system-wide approach. To have a system wide approach these elements need to be aligned by a national quality improvement strategy supported by the necessary implementation and measuring tools discussed in this series of articles.
RECOMMENDATIONS FOR A QUALITY AGENDA IN DENTISTRY

To implement a national quality improvement strategy effectively requires clear objectives that make sense at a local level, mechanisms to achieve these objectives, stakeholders who feel ownership of the strategy and resources to deliver the strategy. A dual focus is required between vertical policy implementation; for example synergy between central NHS England and Local Professional Networks (LPNs) ('big windows') but also the local-local dimension ('small windows'), for example between LPNs and individual practices, which recognises the specifics of implementation at a local level. ${ }^{41}$ The implementation of new policy also often requires bargaining between different stakeholders $^{42}$ and an 'appreciative setting' whereby policy-makers show readiness of mind to respond to an agenda item. ${ }^{43}$ The subsequent agenda must also be seen as amenable to a policy intervention. ${ }^{44}$ Policy change in dental healthcare that privileges quality improvement will depend therefore on the interaction between the setting of the goal of implementing quality improvement in dental care settings at both a national and local level and the necessary resources and strategies to achieve them. ${ }^{45}$ Whether the aim of quality improvement gains enough legitimacy for its implementation will depend on whether this open policy window creates actual policy change. This will require both an agenda and an environment for change. Table 3 outlines some of the key components that will need to be in place to produce a conducive environment.

\section{CONCLUSIONS}

There are four key messages for dentistry from this exploration of quality improvement. First, quality improvement strategies must go hand-in-hand with implementation strategies. ${ }^{14}$ Second, all approaches should be tested for their validity, reliability, acceptability, unintended consequences, feasibility, sensitivity to change, and how communicable or understandable they are. ${ }^{4}$ Third, measurement and indicators should not be used in isolation but as one part of multiple quality improvement initiatives. ${ }^{3}$ Fourth, patients as individuals must not be forgotten. ${ }^{3,46}$ Finally, while 
there is a need to develop, test and validate objective measures of quality, there is a need also for more knowledge on the effectiveness of quality interventions at micro, meso and macros interventions individually and collectively.

1. Campbell $S \mathrm{M}$, Tickle $\mathrm{M}$. What is quality primary dental care? Br Dent J 2013; 215: 135-139.

2. Tickle M Campbell S M. How do we measure quality in primary dental care? Br Dent J 2013; 215: 183-187.

3. Campbell S M, Eriksson T. Multiple strategies for quality improvement and patient safety money alone is not the answer, nor is trust. Conclusions of the 6th EQuiP Invitational Conference April 2011. Eur J Gen Pract 2011; 17: 238-240.

4. Campbell S M, Braspenning J, Hutchinson A, Marshall M N. Research methods used in developing and applying quality indicators in primary care. BMJ 2003; 326: 816-819.

5. Campbell S M, Chauhan U, Lester H E. Primary Medical Care Provider Accreditation (PMCPA): Pilot evaluation. BrJ Gen Pract 2010; 60: 295-304.

6. Hays R B, Bridges-Webb C, Booth B. Quality assurance in general practice. Med Educ 1993; 27: 175-180.

7. Davis D A, Mazmanian P E, Fordis M et al. Accuracy of physician self-assessment compared with observed measures of competence: a systematic review. JAMA 2006; 296: 1094-1102.

8. Braspenning J, Hermans $\mathrm{R}$, Calsbeek $\mathrm{H}$, Westert G, Campbell S M, Grol R. Quality and safety of care: the role of indicators. In Grol R et al. (eds). Improving patient care: the implementation of change in clinical practice, 2 nd ed. Elsevier, in press.

9. Campbell S M, Below G, Brinkmann H, Gerlach F M. External accountability: accreditation and certification for primary care. pp 27-36. In Grol R et al. (eds). Quality management in primary care, Gutersloh: Verlag Bertelsmann Stiflung, 2004.

10. Checkland K, Marshall M, Harrison S. Re-thinking accountability: trust versus confidence in medical practice. Qual Saf Healthcare 2004; 13: 130-135.

11. Buetow S A, Wellingham J. Accreditation of general practices: challenges and lessons. Qual Saf Healthcare 2003: 12: 129-135.

12. Ferlie E B, Shortell S M. Improving the quality of healthcare in the United Kingdom and the United States: a framework for change. Milbank $Q$ 2001; 79: 281-315.

13. Berwick D M. A primer on leading the improvement of systems. BMJ 1996: 312: 619-622.

14. Boaden R, Harvey G, Moxham C, Proudlove N. Quality improvement: theory and practice in healthcare. London: NIHR, 2008.

15. Walshe K. Understanding what works and why in quality improvement: the need for theory driven evaluation. Int J Qual Healthcare 2007; 19: 57-59.

16. Nolan T W. Understanding medical systems. Ann Intern Med 1998; 128: 293-298.

17. Holt V P. Change management in a group dental practice. A consideration of management issues that may arise in a larger dental practice. Prim Dent Care 2007; 14: 149-153.

18. Stevens D P. If you haven't published your work, it's time to start. Qual Saf Healthcare. 2007; 16: 242-243.

19. Deming W E. Out of the crisis. Cambridge, Mass: Centre of Advanced Engineering Study, MIT, 1986.

20. NHS Institute for Improvement and Innovation. Quality and service improvement tools. http://www. institute.nhs.uk/quality_and_service_improvement_ tools/quality_and_service_improvement_tools/ plan do study act.html (accessed 4 October 2012).

21. Grol R, Berwick D M, Wensing M. On the trail of quality and safety in healthcare. BMJ 2008; 336: 74-76.

22. King's Fund. Improving the quality of care in general practice. Report of an independent inquiry commissioned by The King's Fund. London, 2011. http://www.kingsfund.org.uk/publications/ gp_inquiry_report.html (accessed 04 October 2012).

23. Flodgren $G$, Eccles M, Shepperd S, Scott A, Parmelli $E$, Beyer F. An overview of reviews evaluating the effectiveness of financial incentives in changing healthcare professional behaviours and patient outcomes. Cochrane Database Syst Rev 2011; CD009255.

24. Scott A, Sivey P, Ait Ouakrim D et al. The effect of financial incentives on the quality of healthcare provided by primary care physicians. Cochrane Database Syst Rev 2011; CD008451.

25. Christianson J B, Leatherman S, Sutherland K. Lessons from evaluations of purchaser pay-forperformance: a review of the evidence. Med Care Res Rev 2008; 65: 5S-35S.

26. Gillam S, Siriwardena A N, Steele N. Pay-forperformance in the United Kingdom: impact of the quality and outcomes framework - a systematic review. Ann Fam Med 2012; 10: 461-468.

27. Jamtvedt $G$, Young J M, Kristoffersen D T et al. Audit and feedback: effects on professional practice and healthcare outcomes. Cochrane Database Syst Rev 2006; CD000259.

28. Szecsenyi J, Campbell S, Broge B et al. Effectiveness of a quality-improvement program in improving management of primary care practices. CMAJ 2011; 183: E1326-1333.

29. Vingerhoets $E_{1}$ Wensing $M, G r o l ~ R$. Feedback of patients' evaluations of general practice care: a randomised trial. Qual Healthcare 2001; 10: 224-228.

30. Grol R, Wesing M, Eccles M (eds). Improving patient care: the implementation of change in clinical practice. Elsevier, 2005

31. Greenhalgh T, Heath I. Measuring quality in the therapeutic relationship part 1: objective approaches. Qual Saf Healthcare 2010. 19: 475-478.

32. Greenhalgh $T_{1}$ Heath I. Measuring quality in the therapeutic relationship part 2: subjective approaches. Qual Saf Healthcare 2010; 19: 479-483.

33. Cole A, McMichael A. Audit of dental practice record-keeping: a PCT-coordinated clinical audit by Worcestershire dentists. Prim Dent Care 2009; 16: 85-93.

34. Sbaraini A, Carter S M, Evans R W, Blinkhorn A. Experiences of dental care: what do patients value? BMC Health Serv Res 2012; 12: 177.

35. Department of Health. Dental quality and outcomes framework. London: HMSO, 2011. www.gov.uk/ government/publications/dental-quality-andoutcomes-framework (accessed 24 June 2013).

36. Shaw E, Chase S M, Howard J, Nutting P A, Crabtree B F. More black box to explore: how quality improvement collaboratives shape practice change. J Am Board Fam Med 2012; 25: 149-157.

37. Turner D, Tarrant $C$, Windridge K, Bryan S, Boulton $M$, Freeman G, Baker R. Do patients value continuity of care in general practice? An investigation using stated preference discrete choice experiments. J Health Serv Res Policy 2007: 12: 132-137.

38. Mills I, Batchelor P. Quality indicators: the rationale behind their use in NHS dentistry. Br Dent J 2011; 211: 11-15.

39. Department of Health. Equity and excellence: liberating the NHS. Cm7881. London: HMSO, 2010. www.gov.uk/government/publications/liberatingthe-nhs-white-paper (accessed 4 October 2012)

40. General Dental Council. Programme initiation document: revalidation for dentists. London: GDC, 2012.

41. Exworthy, M, Powell M. 2004 big windows and little windows: implementation in the 'Congested State'. Pub Admin 2004; 82: 263-281.

42. Bardach E. The implementation game. Cambridge, Mass: MIT Press, 1977.

43. Vickers G. The art of judgement. London: Sage publications, 1995.

44. Kingdom J W. Agendas, alternatives and public policies, 2nd ed. Atlanta: Addison-Wesley Educational Publishers Inc, 1995.

45. Pressman J, Wildavsky A. Implementation. Berkeley: University of California Press, 1973

46. Heath I, Rubinstein A, Stange K C, van Driel M L. Quality in primary healthcare: a multidimensional approach to complexity. BMJ 2009; 338: b1242. 